\title{
Aspectos imunoistoquímicos da hepatite infecciosa canina
}

\author{
Immunohistochemical aspects of canine infectious hepatitis
}

\begin{abstract}
Maria Andréia Inkelmann ${ }^{\mathrm{I}}$ Bruno Leite dos Anjos ${ }^{\mathrm{I}}$ Glaucia Denise Kommers ${ }^{\mathrm{II}}$ Rafael Almeida FigheraII Claudio Severo Lombardo de Barros ${ }^{I^{*}}$
\end{abstract}

\section{- NOTA -}

\section{RESUMO}

Tecidos de 27 cães que morreram de hepatite infecciosa canina (HIC) foram avaliados por imunoistoquímica (IHQ) para deteç̧ão de antígeno de adenovírus canino tipo 1 (CAV-1), por meio de um anticorpo monoclonal. Os tecidos examinados incluíram fígado, rim, baço, linfonodos, tonsilas, pulmão, intestino delgado, encéfalo e medula óssea. Para cada órgão foram atribuídos graus crescentes (de leve a acentuada) de intensidade de imunomarcação. O antígeno de CAV-1 estava presente na maioria dos órgãos examinados, principalmente em células endoteliais. Relacionando o tempo de evolução clínica da HIC com a intensidade da imunomarcação, o maior número de casos com evolução clínica hiperaguda ou aguda coincidiu com a maior intensidade de marcação do antígeno viral. A IHQ demonstrou ser um teste adequado para a detecção do antígeno de CAV-1 e pode ser usado para o estudo da patogênese da doença.

Palavras-chave: adenovírus canino tipo I, hepatite infecciosa canina, imunoistoquímica, doenças de cães.

\section{ABSTRACT}

Tissues from 27 dogs died from infectious canine hepatitis (ICH) were evaluated by immunohistochemestry (IHC) for detection of canine adenovirus type 1 (CAV-1) antigen using a monoclonal antibody. Evaluated tissues included liver, kidney, spleen, lymph nodes, tonsils, lungs, small intestine, brain, and spinal cord. For each organ increasing degrees (from mild to marked) of intensity of immune staining were ascribed. CAV-1 was detected in most of the evaluated organs, mainly in the endothelial cells. Considering the clinical course of ICH and the intensity of IHC staining, cases with acute and peracute courses had more marked staining. IHC proved to be a reliable test for $C A V-1$ antigen detection and can be used for pathogenesis studies on ICH either in the spontaneous and experimental disease.

Key words: canine adenovirus 1, infectious canine hepatitis, immunohistochemistry, diseases of dogs.

A hepatite infecciosa canina (HIC) é uma doença viral de cães e de outras espécies das famílias Canidae e Ursidae, causada por adenovírus canino 1 (CAV-1), pertencente à família Adenoviridae (GREENE, 2006). CAV-1 tem afinidade por células endoteliais e células hepáticas, está presente em tecidos e em fluídos corporais e é excretado pela urina (HODGMAN \& LARIN, 1953). A HIC freqüentemente tem curso clínico superagudo ou agudo e afeta principalmente cães jovens não-vacinados. Após localização oronasal, CAV1 replica inicialmente nas tonsilas, passa aos linfonodos regionais e atinge o sangue pelo ducto torácico. A viremia dura de quatro a oito dias, mas o vírus é liberado

IPrograma de Pós-graduação em Medicina Veterinária, área de concentração em Patologia Veterinária, Universidade Federal de Santa Maria (UFSM), Santa Maria, RS, Brasil.

"Laboratório de Patologia Veterinária, Departamento de Patologia, UFSM, Santa Maria, RS, Brasil. E-mail: claudioslbarros@uol.com.br. *Autor para correspondência. 
na urina por períodos mais longos. Os sinais clínicos incluem anorexia, apatia, vômito, dor abdominal e diarréia com ou sem sangue (GREENE, 2006). Em alguns casos há sinais neurológicos como incoordenação, convulsões, vocalização e letargia (CAUDELL et al., 2005). A icterícia é incomum ou rara na HIC aguda (INKELMANN et al., 2007), mas pode ser encontrada em alguns cães que sobrevivem à fase fulminante da doença (GREENE, 2006). As lesões macroscópicas incluem petéquias e equimoses disseminadas, líquido serossanguinolento na cavidade abdominal com fibrina, fígado aumentado, com aspecto moteado e recoberto por película de fibrina. As tonsilas estão aumentadas e avermelhadas, e os linfonodos edematosos e hemorrágicos. Freqüentemente há edema da parede da vesícula biliar e hemorragias podem ser observadas no encéfalo ao nível do tálamo, do mesencéfalo, do tronco encefálico e do cerebelo (INKELMANN et al., 2007). As alterações histológicas incluem necrose hepática centrolobular a panlobular, associadas a inclusões intranucleares basofílicas características, que aparecem inicialmente em células de Kupffer e após em hepatócitos viáveis ou degenerados adjacentes a áreas de necrose (GREENE, 2006).

Rotineiramente o diagnóstico de HIC é feito pela associação entre sinais clínicos, lesões macro e microscópicas, porém, outros métodos são utilizados para confirmar a presença do CAV-1 nos tecidos, como, por exemplo, a imunoistoquímica (IHQ), a técnica reação em cadeia da polimerase (PCR) e o isolamento viral (CHOUINARD et al., 1998; CAUDELL et al., 2005). O método imunoistoquímico utiliza anticorpos específicos para detecção da quantidade, da distribuição tecidual e da localização celular dos epítopos imunogênicos em secções histológicas (HAINES \& WEST, 2005).

O objetivo deste estudo foi detectar o antígeno de CAV-1 em tecidos de cães acometidos por HIC, procurando associar esses achados ao curso clínico da doença. Em estudo retrospectivo anterior (INKELMANN et al., 2007), a doença foi diagnosticada em 62 cães necropsiados em nosso laboratório. Em apenas 27 desses casos havia tecidos armazenados em blocos de parafina. Esses 27 casos compuseram os animais deste estudo.

A marcação IHQ foi realizada em secções histológicas de $3 \mu \mathrm{m}$. Para bloqueio da peroxidase endógena, as lâminas foram incubadas com peróxido de hidrogênio a 3\% em metanol. Na recuperação antigênica, foi utilizada a enzima Proteinase K (Dako cód. S3020) $)^{\mathrm{a}}$ por cinco minutos. O anticorpo monoclonal para CAV-1 (VRMD, cód. 2E10-H2)b a uma diluição de 1:100 foi incubado por uma hora, a $37^{\circ} \mathrm{C}$ em câmara úmida. $\mathrm{O}$ anticorpo secundário biotinilado e o complexo estreptavidina-peroxidase (LSAB - DakoCytomation, cód. K0690) a foram incubados consecutivamente por 30 minutos à temperatura ambiente. Tetracloreto de 33' diaminobenzidina (DAB, Sigma, cód. D-5637) ${ }^{\mathrm{c}}$ foi usado como cromógeno. A contracoloração foi realizada pela hematoxilina de Harris e a montagem entre lâmina e lamínula, com meio sintético. Quanto ao número de células positivas, a imunomarcação, nos órgãos examinados, foi classificada como leve, quando algumas poucas células foram marcadas; como moderada, quando uma quantidade média (entre 30 e $60 \%$ ) das células foi marcada e acentuada, quando grande quantidade de células foi marcada (Tabela 1). A imunomarcação ocorria em intensidades variáveis no núcleo e no citoplasma de células endoteliais, hepatócitos e células de Kupffer. A marcação podia preencher todo o núcleo ou ocorrer ao redor de inclusões com centros não-marcados (Figura 1A). No citoplasma a marcação tinha aspecto finamente granular em hepatócitos e difuso em células endoteliais e de Kupffer (Figura 1B); no entanto, algumas inclusões virais não foram marcadas. Esse último achado foi observado no fígado de cães com HIC em outros estudos imunoistoquímicos (RAKICH et al., 1986, CHOUINARD et al., 1998). Isso se deve ao fato de a inclusão ser formada não só por partículas virais, mas também por proteínas que dão origem a uma matriz amorfa presente em quantidades variáveis e que é antigenicamente distinta do vírus (GIVAN \& JÉZÉQUEL, 1969; RAKICH et al., 1986). Nos casos que apresentaram necrose hepática acentuada, a marcação ocorreu em hepatócitos e em células de Kupffer viáveis e também nas áreas de necrose (Figura 1C). No 
Tabela 1 - Intensidade de marcação imunoistoquímica para antígeno de adenovírus canino-1 (CAV-1) por órgão/sistema em 27 cães com hepatite infecciosa canina.

\begin{tabular}{|c|c|c|c|c|c|c|c|c|c|c|c|c|}
\hline Cães & $\mathrm{Ba}^{\mathrm{f}}$ & $B e^{g}$ & $\mathrm{SNC}^{\mathrm{h}}$ & $\mathrm{Co}^{\mathrm{i}}$ & $\mathrm{Est}^{\mathrm{j}}$ & Fig $^{1}$ & $\mathrm{ID}^{\mathrm{m}}$ & $\operatorname{Linf}^{n}$ & $\mathrm{MO}^{\circ}$ & $\mathrm{Pul}^{\mathrm{p}}$ & Rim & To $^{q}$ \\
\hline $1\left(19 d^{b}\right)^{a}$ & $\mathrm{nr}^{\mathrm{r}}$ & $\mathrm{nr}$ & $\mathrm{nr}$ & $\mathrm{nr}$ & $\mathrm{nr}$ & $+s$ & $\mathrm{nr}$ & $\mathrm{nr}$ & $\mathrm{nr}$ & $\mathrm{nr}$ & $-\mathrm{v}$ & $\mathrm{nr}$ \\
\hline $2(7 d)$ & + & $\mathrm{nr}$ & + & $++^{t}$ & $\mathrm{nr}$ & ++ & $\mathrm{nr}$ & + & $\mathrm{nr}$ & $\mathrm{nr}$ & + & $\mathrm{nr}$ \\
\hline $3(3 d)$ & $\mathrm{nr}$ & $\mathrm{nr}$ & + & $\mathrm{nr}$ & $\mathrm{nr}$ & ++ & $++^{u}$ & + & $\mathrm{nr}$ & $\mathrm{nr}$ & + & ++ \\
\hline $4(10 d)$ & + & $\mathrm{nr}$ & $\mathrm{nr}$ & $\mathrm{nr}$ & + & + & ++ & + & $\mathrm{nr}$ & + & + & + \\
\hline $5\left(\mathrm{ND}^{\mathrm{c}}\right)$ & $\mathrm{nr}$ & $\mathrm{nr}$ & + & $\mathrm{nr}$ & $\mathrm{nr}$ & $\mathrm{nr}$ & $\mathrm{nr}$ & $\mathrm{nr}$ & $\mathrm{nr}$ & + & $\mathrm{nr}$ & $\mathrm{nr}$ \\
\hline $6(3 d)$ & $\mathrm{nr}$ & $\mathrm{nr}$ & $\mathrm{nr}$ & $\mathrm{nr}$ & $\mathrm{nr}$ & + & $\mathrm{nr}$ & $\mathrm{nr}$ & $\mathrm{nr}$ & $\mathrm{nr}$ & - & $\mathrm{nr}$ \\
\hline $7(4 d)$ & $\mathrm{nr}$ & ++ & + & $\mathrm{nr}$ & $\mathrm{nr}$ & ++ & ++ & $\mathrm{nr}$ & $\mathrm{nr}$ & ++ & + & $\mathrm{nr}$ \\
\hline $8(10 d)$ & $\mathrm{nr}$ & $\mathrm{nr}$ & + & $\mathrm{nr}$ & ++ & + & ++ & ++ & $\mathrm{nr}$ & ++ & + & $\mathrm{nr}$ \\
\hline 9 (ND) & - & $\mathrm{nr}$ & - & $\mathrm{nr}$ & $\mathrm{nr}$ & + & $\mathrm{nr}$ & $\mathrm{nr}$ & $\mathrm{nr}$ & + & + & $\mathrm{nr}$ \\
\hline $10\left(\mathrm{MS}^{\mathrm{d}}\right)$ & - & $\mathrm{nr}$ & + & ++ & + & - & $\mathrm{nr}$ & $\mathrm{nr}$ & $\mathrm{nr}$ & + & + & $\mathrm{nr}$ \\
\hline 11 (ND) & $\mathrm{nr}$ & $\mathrm{nr}$ & $\mathrm{nr}$ & + & $\mathrm{nr}$ & ++ & $\mathrm{nr}$ & $\mathrm{nr}$ & $\mathrm{nr}$ & + & + & $\mathrm{nr}$ \\
\hline $12(2 d)$ & $\mathrm{nr}$ & $\mathrm{nr}$ & $\mathrm{nr}$ & $\mathrm{nr}$ & $\mathrm{nr}$ & - & + & $\mathrm{nr}$ & $\mathrm{nr}$ & + & & $\mathrm{nr}$ \\
\hline $13(3 d)$ & $\mathrm{nr}$ & $\mathrm{nr}$ & ++ & $\mathrm{nr}$ & ++ & ++ & $\mathrm{nr}$ & $\mathrm{nr}$ & $\mathrm{nr}$ & ++ & ++ & $\mathrm{nr}$ \\
\hline $14\left(18 \mathrm{~h}^{\mathrm{e}}\right)$ & $\mathrm{nr}$ & $\mathrm{nr}$ & ++ & $\mathrm{nr}$ & $\mathrm{nr}$ & ++ & ++ & $\mathrm{nr}$ & $\mathrm{nr}$ & + & + & + \\
\hline 15 (ND) & $\mathrm{nr}$ & $\mathrm{nr}$ & $\mathrm{nr}$ & $\mathrm{nr}$ & $\mathrm{nr}$ & + & $\mathrm{nr}$ & $\mathrm{nr}$ & $\mathrm{nr}$ & $\mathrm{nr}$ & $\mathrm{nr}$ & $\mathrm{nr}$ \\
\hline $16(4 d)$ & $\mathrm{nr}$ & $\mathrm{nr}$ & + & $\mathrm{nr}$ & $\mathrm{nr}$ & + & +++ & $\mathrm{nr}$ & $\mathrm{nr}$ & $\mathrm{nr}$ & + & $\mathrm{nr}$ \\
\hline $17(2 d)$ & + & $\mathrm{nr}$ & +++ & ++ & ++ & ++ & $\mathrm{nr}$ & +++ & $\mathrm{nr}$ & + & + & $\mathrm{nr}$ \\
\hline $18(3 d)$ & $\mathrm{nr}$ & $\mathrm{nr}$ & $\mathrm{nr}$ & ++ & ++ & $\mathrm{nr}$ & ++ & $\mathrm{nr}$ & $\mathrm{nr}$ & + & + & ++ \\
\hline 19 (MS) & $\mathrm{nr}$ & $\mathrm{nr}$ & ++ & +++ & $\mathrm{nr}$ & +++ & $\mathrm{nr}$ & $\mathrm{nr}$ & + & $\mathrm{nr}$ & $\mathrm{nr}$ & $\mathrm{nr}$ \\
\hline $20(6 h)$ & + & ++ & ++ & ++ & ++ & ++ & ++ & + & ++ & ++ & + & ++ \\
\hline $21(6 h)$ & + & $\mathrm{nr}$ & $\mathrm{nr}$ & ++ & + & $\mathrm{nr}$ & $\mathrm{nr}$ & $\mathrm{nr}$ & $\mathrm{nr}$ & + & + & ++ \\
\hline $22(\mathrm{MS})$ & $\mathrm{nr}$ & + & ++ & $\mathrm{nr}$ & $\mathrm{nr}$ & + & $\mathrm{nr}$ & + & $\mathrm{nr}$ & $\mathrm{nr}$ & + & $\mathrm{nr}$ \\
\hline 23 (ND) & +++ & $\mathrm{nr}$ & $\mathrm{nr}$ & + & $\mathrm{nr}$ & ++ & $\mathrm{nr}$ & $\mathrm{nr}$ & $\mathrm{nr}$ & $\mathrm{nr}$ & ++ & $\mathrm{nr}$ \\
\hline $24(12 \mathrm{~h})$ & $\mathrm{nr}$ & ++ & ++ & $\mathrm{nr}$ & $\mathrm{nr}$ & ++ & + & ++ & $\mathrm{nr}$ & + & ++ & $\mathrm{nr}$ \\
\hline $25(12 \mathrm{~h})$ & ++ & $\mathrm{nr}$ & ++ & ++ & $\mathrm{nr}$ & ++ & $\mathrm{nr}$ & $\mathrm{nr}$ & $\mathrm{nr}$ & $\mathrm{nr}$ & $\mathrm{nr}$ & $\mathrm{nr}$ \\
\hline $26(12 \mathrm{~h})$ & $\mathrm{nr}$ & $\mathrm{nr}$ & ++ & $\mathrm{nr}$ & $\mathrm{nr}$ & ++ & ++ & + & $\mathrm{nr}$ & $\mathrm{nr}$ & ++ & $\mathrm{nr}$ \\
\hline $27(5 d)$ & $\mathrm{nr}$ & $\mathrm{nr}$ & ++ & +++ & $\mathrm{nr}$ & +++ & + & +++ & $\mathrm{nr}$ & $\mathrm{nr}$ & +++ & $\mathrm{nr}$ \\
\hline
\end{tabular}

${ }^{\mathrm{a}}$ Evolução clínica, ${ }^{\mathrm{b}}$ dias, ${ }^{\mathrm{c}}$ não-determinado, ${ }^{\mathrm{d}}$ morte súbita, ${ }^{\mathrm{e}}$ horas, ${ }^{\mathrm{f}}$ baço, ${ }^{\mathrm{g}}$ bexiga, ${ }^{\mathrm{h}}$ sistema nervoso central, ${ }^{\mathrm{i}}$ coração, ${ }^{\mathrm{j}}$ estômago, ${ }^{1}$ fígado, ${ }^{\mathrm{m}}$ intestino delgado, ${ }^{\mathrm{n}}$ linfonodo, ${ }^{\mathrm{o}}$ medula óssea, ${ }^{\mathrm{p}}$ pulmão, ${ }^{\mathrm{q}}$ tonsila, ${ }^{\mathrm{r}}$ não-realizado, ${ }^{\mathrm{s}}$ leve, ${ }^{\mathrm{t}}$ moderado, ${ }^{\mathrm{u}}$ acentuado, ${ }^{\mathrm{v}}$ negativo.

rim (Figura 1D), células endoteliais dos tufos glomerulares apresentando marcação acentuada. Marcação em numerosas células reticuloendoteliais foi observada em linfonodos, no baço (Figura 1E) e na medula óssea. $\mathrm{O}$ antígeno foi detectado no endotélio de vasos do encéfalo (Figura $1 \mathrm{~F}$ ), principalmente em filhotes de até um ano de idade, não-vacinados, e que morreram de forma hiperaguda ou aguda. A marcação imunoistoquímica em células endoteliais de vários órgãos confirma a predileção de CAV-1 por células endoteliais e explica as lesões hemorrágicas encontradas na doença espontânea (INKELMANN et al., 2007). Neste estudo, os casos com curso clínico superagudo ou agudo apresentaram maior intensidade de imunomarcação (moderada ou acentuada). Achado semelhante foi relatado em outro estudo imunoistoquímico no encéfalo de filhotes de cães com HIC (CAUDELL et al., 2005). Já os casos estudados que apresentaram imunomarcação leve tiveram curso clínico mais longo.

A imunoistoquímica é eficaz na demonstração da distribuição do antígeno viral em tecidos de cães com HIC. A imunomarcação do CAV-1 nos diversos tecidos demonstra a disseminação do vírus pelo organismo, principalmente afetando as células endoteliais. A correlação entre a intensidade de imunomarcação e o tempo de evolução clínica demonstrou grande quantidade de antígeno viral nos casos hiperagudos e agudos.

Ciência Rural, v.38, n.9, dez, 2008. 


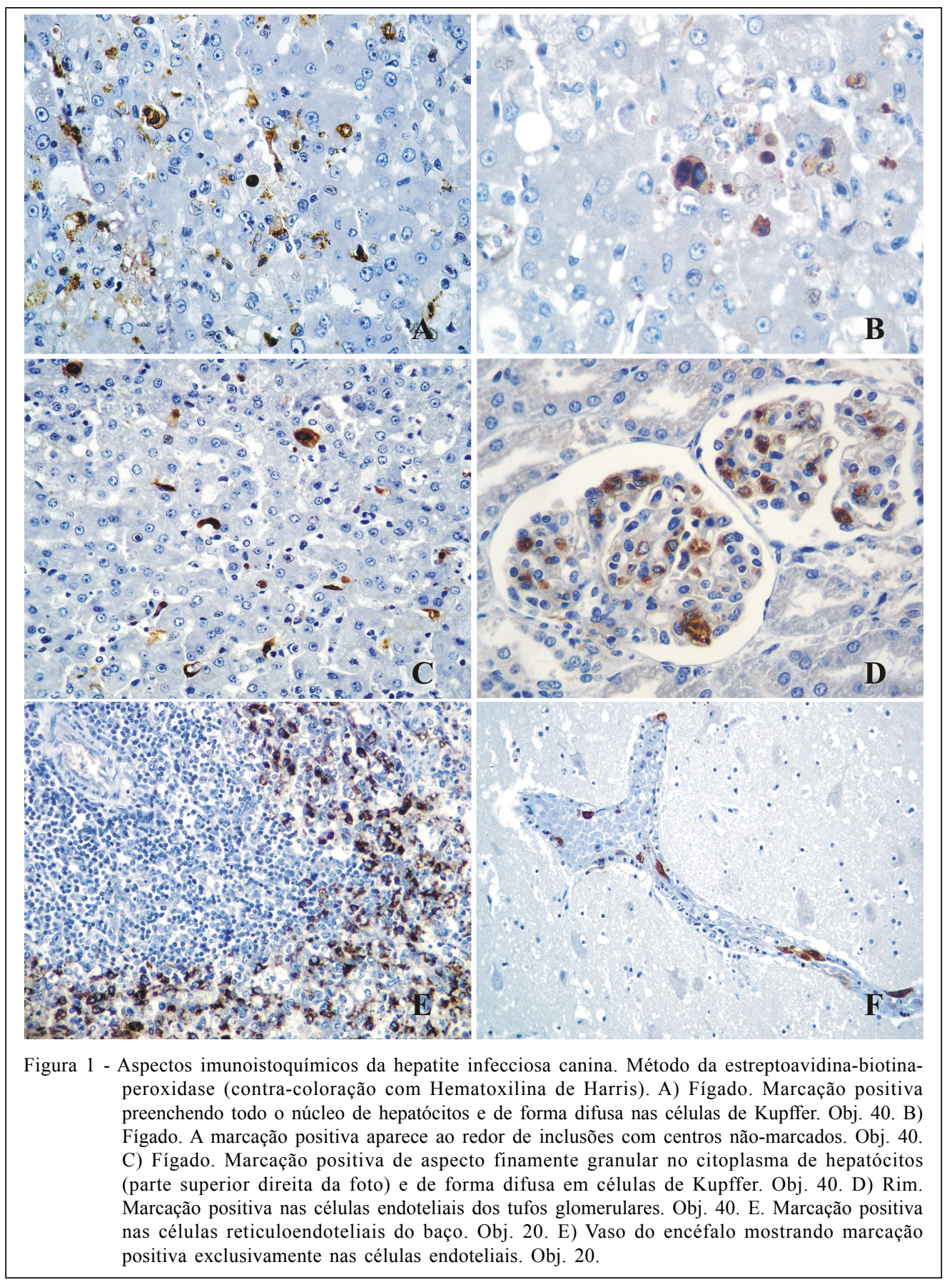

\section{FONTES DE AQUISIÇÃO}

aDakoCytomation, Carpinteria, Califórnia, Estados Unidos. ${ }^{b}$ VRMD, Inc., Pullman, Estados Unidos.

'Sigma, Saint Louis, Missouri, Estados Unidos.

\section{REFERÊNCIAS}

CAUDELL, D. et al. Diagnosis of infectious canine hepatitis virus (CAV-1) infection in puppies with encephalopathy.
Journal Veterinary Diagnostic Investigation, v.17, p.5861, 2005.

CHOUINARD, L. et al. Use of polymerase chain reaction and immunohistochemistry for detection of canine adenovirus type 1 in formalin-fixed, paraffin-embedded liver of dogs with chronic hepatitis or cirrhosis. Journal Veterinary Diagnostic Investigation, v.10, p.320-325, 1998 .

GIVAN, K.F.; JÉZÉQUEL, A. Infectious canine hepatitis: a virologic and ultrastructural study. Laboratory Investigation, v. 20, p. $36-45,1969$ 
GREENE, C.E. Infectious canine hepatitis and canine acidophil cell hepatitis. In: Infectious disease of the dog and cat. 3.ed. Philadelphia: Saunders-Elsevier, 2006. Cap.8, p.41-47.

HAINES D.M.; WEST K.H. Immunohistochemistry: forging the links between immunology and pathology. Veterinary Immunology and Immunopathology, v.108, p.151-156, 2005.
HODGMAN, S.F.J.; LARIN, N.M. Diagnosis of canine virus hepatitis (Rubarth's disease). Veterinary Record, v.65, p.447$450,1953$.

INKELMANN M.A. et. al. Hepatite infecciosa canina: 62 casos. Pesquisa Veterinária Brasileira, v.27, p.325-332, 2007.

RAKICH, P.M. et al. Immunohistochemical detection of canine adenovirus in paraffin sections of liver. Veterinary Pathology, v.23, p.478-484, 1986. 